\title{
É possível a volta para a escola
}

\author{
Lígia Costa Leite
}

\section{RESUMO}

\begin{abstract}
Este artigo reflete sobre a possibilidade de oferecer educação escolar a meninos de rua. O conceito de "invencíveis culturais" é capital para o entendimento da idéia de que estes grupos apresentam diversas formas de resistência frente ao sistema instituído, não aceitando passivamente o modelo a eles dirigido. Desta forma, mais que expulsos da escola, eles a expulsaram de suas vidas, pelo distanciamento entre a realidade vivida e a tratada nos bancos escolares. A análise da história e das formas de opressão, dos conceitos e representações socialmente construídos, do atendimento à criança pobre instituída, nos apresenta algumas respostas. Partindo da experiência desenvolvida entre 1983 e 1989 , na Escola Tia Ciata, na cidade do Rio de Janeiro, propomos novas concepções metodológicas onde a cultura destes jovens seja valorizada e priorizada no processo escolar.

Palavras-chave: meninos de rua, invencíveis culturais, exclusão e educação.
\end{abstract}

\begin{abstract}
This article describes the possibilities of offerring education to street boys and girls. The concept "culturaly unbeatable" is essential for one to understand that these groups present several ways of resisting an established system, not passively accepting a model which already exists. This way, instead of being expelled from school, these street boys and girls expelled school from their lives, for being distant from reality and the way reality is treated in schools. The analysis of history and its oppressive ways, concepts and socially built representations, attending to poor children leads us to some answers. From experiments, held from 1983 to 1989 , at Aunt Ciata School in Rio de Janeiro, new methodologic concepts to teach these young felllows, in scholastic process, are proposed.
\end{abstract}

\section{Introdução}

Gostaria de homenagear, com esta fala, dois grandes brasileiros e meus mestres, Darcy Ribeiro e Paulo Freire.

Neste artigo, sem me estender na profundidade e abrangência do tema "a escolarização de excluídos e a escola que temos hoje", levantarei alguns pontos de problematização da questão, levando em conta minha experiência com a escolarização de adolescentes de rua do Rio de Janeiro.

A experiência desenvolvida entre 1983 e 1989 na Escola Tia Ciata, uma escola da rede municipal do Rio de Janeiro, tinha como objetivo principal atuar naquilo que considero o problema da adolescência e infância pobres - a falta de escolaridade para integração no mundo oficial, que é letrado. Entendia a importância primordial da escolarização na educação dessa população, tomando por base o pressuposto de Darcy Ribeiro: "a verdadeira profissionalização é o ato de ler, escrever e contar. Com essa singela sabedoria Lula quase chega à presidência do Brasil, sem ela teria ficado varrendo a porta da fábrica”.

$\mathrm{Na}$ ocasião da formulação e implantação da Escola, tomei por base estudos da realidade educacional do Rio de Janeiro e dos livros didáticos utilizados nas classes de alfabetização, especialmente na zona mais pobre da cidade, onde se concentram os candidatos a serem meninos de rua. Sobre os livros didáticos nem é preciso falar muito, pois vários trabalhos têm sido apresentados demonstrando a discriminação e a falta de criatividade neles contidos, levando o aluno a "emburrecer" e ser considerado incapaz de aprender.

Rubem Alves deixa muito claro o mal produzido por uma escola com métodos e conteúdos mutiladores para a vida afetiva e psíquica de seu aluno pobre. Contrariamente ao esperado pelo senso comum ele afirma: "Por vezes, a maior prova de inteligência se encontra na recusa em aprender. [...] Afinal de contas as escolas são instituições dedicadas à destruição das crianças. Algumas, de forma brutal. Outras, de forma delicada". 
A necessidade de se instituir um projeto especial para adolescentes analfabetos partiu do Plano Setorial de Educação do Estado do Rio de Janeiro - 1983-1986, quando foi constatado -a partir de levantamentos estatísticos do censo demográfico e escolar - que mais de um milhão de jovens da nossa cidade podiam ser considerados analfabetos funcionais, ou seja, podiam desenhar o nome ou ler símbolos presentes nas ruas ou nos anúncios, como Coca-cola, sabão em pó Pop, Centro, Zona Sul, Copacabana etc., mas não sabiam como receber ou transmitir mensagem ou informação escrita. Assim, marginalizados com respeito ao principal veículo de comunicação de uma sociedade letrada, estavam condenados a serem também marginais no plano socioeconômico. Eram, enfim, os excluídos da escola ou repetentes crônicos da 1. a série do ensino fundamental que não conseguiam progredir nos estudos.

Pelos números acima apresentados, justificava-se uma proposta com metodologia escolar diferente, uma proposta que levasse em conta a realidade de onde esses jovens eram originários e de onde estavam inseridos, suas vivências, histórias de vida, expectativas, tornando-os sujeitos de sua própria aprendizagem.

O fato é que o Brasil, apesar de pretender se tornar uma nação e uma grande família solidária, não se preocupou em escolher nenhuma das "duas vertentes básicas pelas quais as nações se encaminharam para alfabetizar sua população. Uma é a vertente luterana, outra é a cívico-napoleônica”.

A primeira, a religiosa, foi instituída por Lutero há 500 anos. Partia do princípio que "ler é a forma suprema de rezar. Em conseqüência, fez das velhas igrejas, escolas; ou criou novas escolas, que eram igrejas". Lutero partia do princípio que todos deveriam poder ler e interpretar a Bíblia, tirando a hegemonia dos sacerdotes e bispos católicos, os únicos que sabiam latim e que para isso eram "autorizados" pelo Papa. Lutero traduziu a Bíblia para o alemão e levou todos às igrejas para aprenderem a ler, tendo como material a própria Bíblia.

A ausência de propostas educacionais, sejam a dos exemplos acima, seja, uma outra mais próxima das características do povo brasileiro, criou jovens "pauperizados pela ociosidade" (no dizer do Jornal O Apóstolo, do Rio de Janeiro, em 1884) e que se tornaram, desde então, parte de um enorme contingente que freqüenta a escola da vida e das ruas, uma escola que os faz sábios, porém “inúteis" à Pátria.

Sempre é bom lembrar que a Lei de Diretrizes e Bases (LDB), que institui o ensino público, gratuito e laico obrigatório dos 7 aos 14 anos, foi sancionada em 1961, após 13 anos de discussão no Conselho Federal de Educação e Congresso Nacional. Esta Lei foi uma vitória de Darcy Ribeiro, então Ministro da Educação. A LDB, no entanto, ainda não foi implantada em sua plenitude e até hoje é enorme o contingente de alunos "aptos" que a escola classifica como "inaptos" ao não se enquadrarem dentro do conteúdo, regras e disciplina propostos.

Mesmo assim, não é totalmente verdadeira a afirmação, comum nas críticas que têm sido feitas sobre o sistema escolar, de que esse enorme contingente é jogado nas ruas pela escola brasileira. Eles é que expulsam as escolas de suas vidas e vão às ruas procurar outras possibilidades. De fato, eles até gostariam de freqüentar uma escola, pelo símbolo social que ela representa, mas consideram que não vale a pena "perder" tempo com um conteúdo escolar desmotivador e distanciado da realidade vivida por eles. Esses são aqueles que qualifiquei de "invencíveis culturais" - ou seja, aqueles que, por um lado, não conseguiram vencer a resistência e serem reconhecidos socialmente, por outro, não se deixam ser vencidos em suas formas sociais, ao aceitar passivamente o modelo de educação a eles dirigido.

Num parênteses gostaria de definir o significado da palavra cultura utilizado por mim: "Cultura" é parte integrante do cotidiano do ser humano, ela é uma rede simbólica que envolve a todos desde que nascemos e até depois da morte, definindo uma maneira peculiar de ver o mundo e nele atuar. São os valores, as formas religiosas, as formas de ver, pensar e sentir a vida.

Entendendo isso, como afirmava Paulo Freire em sua luta por uma educação mais democrática, é fundamental observar que experiências são acumuladas com a vida nas ruas - suas histórias de vida - que a escola ignora ou procura ignorar. Se ela reconhecesse esses saberes, conquistados no abandono, como legítimos, ela seria capaz de fornecer um ensino de qualidade e motivador para seus alunos. Ignorando-os, ela só é capaz de reproduzir conhecimentos não relevantes para suas vidas sociais, empobrecidos da espontaneidade criadora, e desestimulantes para que uma aprendizagem efetiva viesse a ocorrer.

Um exemplo é a afirmação de Maurício, 16 anos, em 1988, aluno da Escola Tia Ciata: “A gente foge de casa e quem ensina a gente é o mundo". Ou a de Alexandre, 17 anos: "Às vezes a rua se torna casa, escola... Não dá uma vida melhor, mas mostra como se deve viver. $\mathrm{Na}$ rua, os meninos vão buscar os ensinamentos que a família e a escola não deu para eles".

Foi justamente na Escola Tia Ciata, a qual compartilhava com outras nove escolas um complexo educacional, criado por Darcy Ribeiro de modo a justificar a construção do Sambódromo, que comecei a vivenciar o peso negativo dos estigmas que os "invencíveis" - aqueles que escolheram as ruas para fugir das 
perturbações mentais, da fome e da invisibilidade social - carregavam. Estigmas estes que eram traduzidos em qualificações negativas para a Escola - como A fina flor da passarela ou Delinqüência juvenil - e em pena e vitimação para os profissionais que ali trabalhavam, por terem que executar um trabalho inútil, como "malhar em ferro frio".

Foram importantes essas demonstrações, para que eu tivesse consciência do quanto profundo era o preconceito e o incômodo que a simples presença dessas irreverentes criaturas causavam àquele ambiente escolar dirigido a alunos mais controláveis.

Importantes, também, para ter consciência de que para formular uma metodologia de trabalho, numa escola, que levasse à superação de situações de descrença e desvalorização por parte dos alunos e de preconceito e medo por parte da sociedade, o primeiro e grande desafio era conhecer melhor a quem se pretendia dirigir a ação educativa.

A simples existência desses jovens e adolescentes procurando abrigo e consolo aos olhos de todos, nos sinais, nas ruas, nas praças, denunciava o descaso social com eles e ameaçava a imagem do Brasil como um país harmonioso. Conhecê-los melhor era estar aberta para entender o significado que a rua tem para eles: ela é generosa - as nossas instituições não são - é agasalhadora da miséria, é a única possibilidade de aspiração de amor, dinheiro, felicidade, prazer, enfim, de reconhecimento.

Sei que aqui estou criando uma polêmica, uma vez que o senso comum tende a questionar a alegria e o prazer dessa vida nas ruas. Afinal, como poderiam existir seres humanos nas ruas, sem abrigo e proteção, à mercê do frio, da chuva, do desamparo, da violência, sem comida garantida, não tendo uma família nos moldes tradicionais, conseguindo sobreviver na insalubridade e aridez e ainda ter momentos de alegria e prazer?

A comprovação dessa alegria aparece em várias falas de jovens com os quais trabalhei ou estou trabalhando agora. Por exemplo, André, membro do Grupo de Reflexão que funciona no Instituto de Psiquiatria da UFRJ, 17 anos, nas ruas desde os 10 anos, fala:

Quando eu saí de casa, foi porque eu quis. Não dava bola para nada, sempre fui um nada [...] O que eu queria mesmo era construir uma vida longe deles (os pais). O diferente nas ruas era que os meninos de rua são alegres. Em casa era tudo triste. Eu olhava nos olhos deles (meninos) e não via tristeza. [...] A criança para se sentir em paz tem que ter liberdade. [...] Foi aí que eu fui aprender na rua a "roubar" das pessoas todo o conhecimento que eu precisava para vencer o jogo da vida.

Mas esta não é a opinião e a visão expressas nos jornais, nem pelas autoridades de nossa sociedade, que passam deles imagens conflitantes, oscilando entre uma "infelicidade", que só seria superada pela caridade, e uma "monstruosidade", quase não os reconhecendo como seres humanos.

Isso aparece claramente nos meios de comunicação desde o século XIX - editoriais de jornais e artigos de opinião - que qualificam esses jovens com imagens negativas do ponto de vista do bem e da ordem social - "monstros", "vermes", "bandidos", "facínoras", "perversos", "libertinos", "ociosos", “ousados", entre outras. 1993:

Um exemplo é a carta do leitor Adhemar Pereira da Cruz, publicada em O Globo, em 28 de julho de

Os meninos de rua que assaltam, estupram, saqueiam, matam não são monstros? É pouco manifestar o horror que os menores delinqüentes espalham pela cidade. A sociedade precisa se unir contra eles. [...] É imperioso procurar uma explicação para os crimes sem desculpas que os menores de rua praticam.

Ou ainda em manifestações públicas, como a do Presidente do Clube de Diretores Lojistas do Rio de Janeiro, Silvio Cunha, que com a maior sinceridade e simplicidade disse: "Quando se mata um pivetinho, está se fazendo um benefício à sociedade" (O Globo, 12 jan. 1991).

Com essas imagens, esses jovens tornaram-se um fetiche para as instituições educacionais, um mito difícil de ser desfeito e que conduz à impossibilidade de se enfrentar o problema com a realidade que ele comporta, uma vez que mito, segundo Fernando Pessoa, "é o nada que é tudo".

Mas é importante ressaltar que, para quem quer trabalhar e educar esses jovens, é necessário desvelar esta sombra ameaçadora, contextualizando-os historicamente. Para isso, também é importante refletir sobre o fracasso das instituições criadas para "assisti-los", que se limitaram a procurar enquadrá-los em engrenagens anônimas de uma máquina administrativa e, como conseqüência, reprimindo suas formas culturais. 
Ainda com essa preocupação, é preciso perceber que do outro lado da ordem oficial, na ponta extrema dessa realidade, encontram-se os reais meninos e adolescentes de rua com suas emoções, necessidades, desejos, expectativas de serem aceitos, reconhecidos, absorvidos pela sociedade.

A fala de Rita, menina de rua de Copacabana, em 1995, traduz essa vivência e expõe sua versão:

\begin{abstract}
As pessoas têm raiva, têm pena, mas a gente também, a gente tem raiva das pessoas e tem pena. Tem pena porque às vezes tem gente que passa aqui, nós tá tudo deitado e as pessoas vêm aqui, pra passar aqui e fica com medo de passar aqui. Vê um monte de menino de rua que é bandido, fica com medo. Às vezes dá raiva, mas às vezes dá pena. A gente quando tá junto, fazendo as cama prá dormir, a gente não vai fazer nada com quem passa, a gente vai dormir mesmo.
\end{abstract}

Rita nos diz, com sua afirmação, que fica com pena das pessoas terem medo deles no momento em que eles estão se preparando para dormir e por isso não é hora de roubar. Mas, como as pessoas que passam poderiam saber qual é o momento apropriado para o roubo? Uma das hipóteses que venho levantando é que o roubo, para eles, significa reconhecimento por alguém que tenta os ignorar. Marcelo, aluno da Escola Tia Ciata, após ter sido preso num ônibus, assaltando, em 1989 afirmou: "Tia, eu nem estava com vontade daquilo, mas a mulher fingiu que não me viu... escondeu o relógio... aí é que deu vontade mesmo e eu roubei ela".

Esse desconhecimento dos hábitos e costumes de realidades que não dominamos é próprio do etnocentrismo cultural, ou seja, julgarmos a partir dos nossos valores as formas de viver de outros contextos culturais.

Utilizando o pensamento de Lévi-Strauss essas expressões culturais podem ser consideradas noções "selvagens" de vida:

\begin{abstract}
A atitude mais antiga e que repousa, sem dúvida, sobre fundamentos psicológicos sólidos, pois que tende a reaparecer em cada um de nós quando somos colocados numa situação inesperada, consiste em repudiar pura e simplesmente as formas culturais, morais, religiosas, sociais e estéticas mais afastadas daquelas com que nos identificamos. 'Costumes de selvagens', 'isso não é nosso', 'não deveríamos permitir isso', etc., um sem número de reações grosseiras que traduzem este mesmo calafrio, esta mesma repulsa, em presença de maneiras de viver, de crer ou de pensar que nos são estranhas.
\end{abstract}

Assim, é preciso procurar entender e decifrar as formas de vida desses jovens, para os quais vamos dirigir nossa ação de educadores e como elas podem ser trabalhadas educativamente, numa perspectiva da escolaridade, sem que eles se sintam desrespeitados como pessoas singulares e dignas de reconhecimento.

Como exemplo, vou abordar aqui uma das características dos "invencíveis" mais apontadas pela ordem oficial - referindo-me à opinião pública - como sendo o núcleo do problema da infância excluída socialmente - a "liberdade" excessiva que eles têm. Liberdade que leva à ociosidade e "corpo vadio é oficina de satanás", diz o dito popular.

A liberdade, para o jovem excluído, traz uma conotação de pertencimento, de identidade, de diferenciação, de singularidade. Liberdade como forma de sobrevivência psicossocial, liberdade como saúde mental, liberdade como conquista de um reconhecimento que lhe tem sido negado.

Como contraponto a essa liberdade identificada como ociosidade, vadiagem, enfim, um perigo para a ordem da nação, surgem, ainda no século XIX, as propostas oficiais com o objetivo de "curar uma patologia", ou seja, reprimir uma cultura que foge do padrão considerado civilizado. Assim, com a justificativa de abrigar e proteger uma infância desamparada, surgem os internatos, ou seja, instituições totais que se destinam à educação da "infância culpada" - uma qualificação sutil do "mundo da ciência" para se permitir tirá-los da vista, sem que para isso levasse à sociedade a se sentir culpada. Neste enfoque a culpa é da própria criança por estar na rua, expondo-se e propiciando um "espetáculo deprimente aos olhos do público".

As instituições criadas para esse fim tinham como meta "corrigir" formas de vida e também "reprimir" a ociosidade, à qual essa infância era submetida pela ausência de oportunidades sociais, ociosidade essa que representava um inimigo ao bem da pátria. Note-se que, após quase um século, essas propostas de retirar das ruas ou simplesmente esconder a miséria e a irreverência em instituições fechadas não lograram êxito, como nós podemos ver hoje.

Neste quadro, poderíamos perguntar: como fazer para mudar esse destino a que o Brasil parece ter escolhido para si?

Segundo Milton Santos, geógrafo e professor da Universidade de São Paulo: 
[...] o futuro da sociedade não pode significar a perpetuação do presente. O futuro deve ser o novo, o inusitado, algo que rompe com o atual e elimina as repetições. E esse futuro, assim pensado, será propiciado pelas bordas do sistema, os fragmentos, e não pelo núcleo, o miolo, que reproduz o sistema sem perspectivas de mudança.

O miolo recebe tudo pronto, não questiona e não possibilita modificações no status quo. Além disso, ele nunca conseguiu entender a dinâmica das cidades uma vez que aceita como verdadeiro aquilo que é dito e opinado pela imprensa e pelos teóricos sociais.

Ainda segundo Milton Santos, "as possibilidades de se constituir no futuro novas formas de ser e de existir são criadas pelos fragmentos sociais - eles são divergentes e contraditórios e por não serem escravos da razão hegemônica produzem uma nova cultura". Os fragmentos, para Santos, são constituídos de camadas sociais que estão nas bordas do sistema, que não têm possibilidade de se modernizar, como prevê o sistema, por não ter poder de compra, mas que mantêm a sua identidade procurando alternativas de sobrevivência e assim criam e recriam as cidades todos os dias.

É possível, então, dizer que os meninos de rua, "invencíveis culturais", são parte desses fragmentos, já que buscam a cada dia inventar novas formas de burlar a realidade e a morte. Infelizmente não são escutados, uma vez que a sociedade se nega a reconhecê-los com sua riqueza cultural. Isso se dá, possivelmente, por ser difícil aceitar o outro, o diferente, o que traz uma verdade nova sob outro ponto de vista.

Em síntese, mesmo sem reconhecê-los oficialmente e dar-lhes oportunidades reais, as autoridades e a sociedade civil, de modo geral, vêm se ocupando em qualificá-los, incriminá-los ou culpar outras instâncias pela impotência em solucionar a questão.

Gostaria de propor, enfim, uma alegoria como modo de se unir duas realidades culturais diferentes e que se rejeitam, apesar de conviverem em constante ameaça. Seria possível imaginar um casamento oficial entre Apolo - o deus sol da mitologia grega, o símbolo da organização, da higiene, da razão, da pureza, da harmonia, da moralidade e vencedor das trevas e do demônio - e Dionísio - o deus do êxtase, da desorganização, da falta de limites, da libertinagem, da sensualidade, da ousadia, do rompimento das regras pré-estabelecidas, enfim, a representação do demônio ou satanás? O que quero dizer é como assumir a convivência entre a racionalidade, a organização, explorando a transformação, o rompimento de limites, a explosão, tornando o Brasil um país singular e com possibilidades de crescimento fora dos padrões ocidentais de cultura. Esse casamento já existe na circularidade cultural, no jeitinho brasileiro, nos lances do futebol etc. Só é preciso ser aceito oficialmente e incorporado ao pensar social.

E, numa analogia final, gostaria de concluir apresentando outro mito, um mito que coloca o sentido da vida nas ilusões e nas idéias. O mito de Sísifo. Albert Camus descreve Sísifo como o herói do absurdo, por ele ter voltado à vida depois de morto duas vezes, inclusive tendo aprisionado Tanatos, o senhor da morte. Daí recebe o castigo dos deuses para rolar um rochedo incessantemente até o cimo de uma montanha, de onde a pedra caia de novo por seu peso. "Os deuses tinham pensado, com as suas razões, que não existe punição mais terrível do que o trabalho inútil e sem esperança".

Assim pensam muitos sobre nós, educadores, que atuamos com uma clientela considerada doente e irrecuperável, devido aos traumas e carências sofridos. No entanto, nós podemos nos sentir como Sísifo, porque para ele seu trabalho não era inútil muito menos um castigo, como queriam os deuses. Camus afirma:

Sísifo ensina a fidelidade superior que nega os deuses e levanta os rochedos. Ele também acha que tudo está bem. Esse universo doravante sem senhor não lhe parece nem estéril nem fútil. Cada um dos grãos de pedra, cada clarão mineral dessa montanha cheia de noite, só para ele forma um mundo. A própria luta em direção aos cimos é suficiente para preencher um coração humano. É preciso imaginar Sísifo feliz.

\section{REFERÊNCIAS}

ALVES, R. Estórias de quem gosta de ensinar. São Paulo: Cortez.

CAMUS, A. O mito de Sísifo. Rio de janeiro: Guanabara, 1989.

LEITE, L. C. A razão dos invencíveis. Rio de Janeiro, 1996. Tese (Doutorado) - ECO, Universidade Federal do Rio de Janeiro. 
LÉVI-STRAUSS, C. Race et histoire. Paris: Denoël, 1987.

RIBEIRO, Darcy. Nossa escola é uma calamidade. Rio de janeiro: Salamandra, 1984.

RIO, João do. A alma encantadora das ruas. Rio de Janeiro: SMC, 1987. 